obliterate its cavity, by what we may call a plastico-secretive action, similar to that which may be produced by injecting a solution of tincture of iodine into serous cysts or the tunica vaginalis, as in the operation for hydrocele.

Gradually increased doses of iodide of potassium, from two to twenty grains, should be given internally, in some bitter infusion; and an ointment, made of one drachm of iodide of potassium to an ounce of lard, must be carefully rubbed-in morning and evening. After persevering in this treatment for several months, the tumour will feel softer; but it may become painful to pressure, and be the seat of inflammatory action, giving rise to fever. These accidents may be effectually combated by fomentations, poultices, tepid baths, or local bleeding, as the case may require.

My friend, Dr. Rayer, has tried this treatment in thirtythree cases. Three of his patients, who had ovarian tumours as large as a child's head, were completely cured after several months' treatment. In one of his patients, the treatment brought on acute peritonitis, which became chronic, and the patient now only complains of a slight but constant pain in the left iliac fossa. The other patients were discouraged by the tediousness of the treatment, or alarmed at some of the inflammatory symptoms it gave rise to, and discontinued it.

From what has preceded, I may be allowed to infer that iodine is the most valuable remedy which the physician possesses to combat ovarian dropsy; and as its powerful action may be kept under control, (for by its careful exhibition no harm is done to the patient's constitution, even if the ovarian tumour remains unaltered, I do not hesitate to say that in all cases of small or moderate-sized ovarian cysts, iodine should be given with perseverance. At the same time, its action should be carefully watched, and not allowed to produce a spontaneous rupture of the cyst; for though this accident has been often followed by cure, it is always attended by considerable danger. I should not think myself justified in recommending a treatment, of which such an accident would form an essential link in the chain of circumstances.

F. Electricity. - It appears that electricity has been made use of in the treatment of ovarian dropsy; I know not under what form, or with what success; but I cannot help thinking that so powerful an agent might be effectually made use of to bring about that peculiar softening of the tumour mentioned by Dr. Hamilton and others as the preparatory step towards cure, and the ultimate absorption of its contents.

G. A cupuncture. W Wat $I$ have said on electricity applies to acupuncture. In THE LANCET, $I$ find a case recorded in which it was successfully employed by Dr. Robert D. Thomson; and it might again be tried instead of letting the disease take its natural course, or treating it by the most dangerous modes of cure.

Such are the various plans of medical treatment which have been employed in ovarian dropsy; but they are only available in cases of monolocular cysts, when the tumour is not too large, and the health of the patient is otherwise good. I shall next bring under review the surgical treatment of ovarian dropsy.

Gloucester-road, Hyde-park.

$$
\text { (To be continued.) }
$$

\section{REPORT OF A}

\section{CASE OF HYDROPHOBIC MANIA SUCCESSFULLY TREATED WITH CHLOROFORM.}

By R. Y. ACKERLEY, Esq., M.R.C.S.E., Liverpool.

Jовм L-, a labourer, aged thirty, of a phlegmatic temperament, had been residing for about a fortnight in his house by himself, (his wife having gone into the country with a sick child, for change of air;) and had been complaining of not feel. ing quite well for a week or ten days; his general habits were very quiet, sober, and peaceable, but for the last few days he had been exceedingly irritable towards his fellow workmen. Between ten and eleven years ago he had been bit in the leg by a rabid cat, and the wound had been cauterized with a hot iron at the time. His general health had been very good.

On the 14th of January, when his wife returned, he complained of lowness of spirits and a giddiness in his head; passed a very restless night; said he feared he was going to lose his senses, occasionally mentioned the bite of the cat, and attributed his illness to that canse, examining at the same time the cicatrix on his leg. He did not go to work on the following day, but rambled, and said he feared that something dreadful was going to happen to him; took his food well; had frequent flushings in the face, with occasionally a feeling of coldness in the back, but no distinct rigor, nor headach. $\mathrm{He}$ got some medicine from a druggist, which purged him; the evacuations were very dark; had no sleep all night.

On the following day (Saturday) he thought himself rather better, felt hungry, and wanted breakfast and dinner early, of which he partook freely; at supper he could not eat, but looked wild, and rambled in his conversation. At eleven P.M. my assistant, Mr. Bryde, saw him: his tongue was red and moist pulse 95 ; skin hot and dry. Ordered five grains of calomel immediately, to be followed by a saline febrifuge mixture every four hours, and a blister to the nape of the neck. Had restless sleep during the early part of the night, but none towards morning; took his medicine regularly during the night, but towards noon was unable to swallow liquids, which were rejected with great force by a spasmodic action of the muscles of deglutition. He refused drink during the remainder of the day, but took his medicine from me in the evening with great difficulty. After sleeping about two hours, he was more calm, but not quite collected; is constantly rambling about a cat fancies he sees one in the room, and asks his brother to kill it. Pulse 90 and soft; skin hotter than natural; complains of a heavy beating and shooting pain about the diaphragm, and gid. diness in the head; is constantly wiping a viscid saliva from his mouth; the eye very wild; he shrinks under the bed-clothes when spoken to, and tries to hide himself. I examined the leg and found the cicatrix quite natural; tried every means to banish the idea of hydrophobia from his mind. Ordered ex. tract of Indian hemp, five grains every four hours.

January 18th.- Has passed a better night; appears very sullen, and either unable or unwilling to answer any questions; frequent flushings of the face, and a horror of fluids when offered to him; at my request he attempted to drink a little tea, but when he got it into his hand he turned from it with dread. Has taken nothing but his medicine during the night pulse 92 ; tongue red, but not dry; slight epigastric tenderness; skin cool; pupils dilated; conjunctive not at all injected. The Indian hemp to be continued.-Three P.M.: sullenness increased; will not answer any questions, and refuses everything offered to him; in other respects much the same as in the morning. Every precaution was now taken that he should not do any injury to himself or others, as it was feared that furious mania might supervene. My friend, Mr. Bainbrigge, met me in consultation at ten P.M. Has taken his medicine better, and also a cup and a half of tea, which he sucks through his teeth; he still refuses to answer any questions.

19th.-Sleepless night; he talks of the cat, and attributes his illness to that cause, but still will not speak when spoken to. Bowels constipated; tongue dry and red. Ordered, calomel, ten grains, to be taken immediately.

20th.-No sleep all night; left eye injected; the spasmodic contractions of the muscles, which at first were confined to the throat, have now extended to the limbs, the elbows being drawn very much backwards towards the spine; the wrists and feet also distorted. Has been very violent during the night, requiring the assistance of four men to hold him, and shouting and struggling incessantly.

We now came to the determination of trying the chloro. form, which put him to sleep in about three minutes; he did not awake again for three-quarters of an hour; when he appeared much more calm, recognised his wife, and kissed and embraced her; deglutition better; the bowels had not acted; pulse ninety. To have four ounces of infusion of senna, and a blister over the scalp: in the evening we found him much quieter: the bowels had acted; passes his urine and stools involuntarily. The effect of the chloroform was so decided in the morning that we resolved to repeat it, which was accordingly done with the same beneficial effect. The cerebral symptoms, however, returned about one in the morning, and at our visit at ten o'clock on the 21 st, we found him a perfect maniac; conjunctiva of both eyes much suffused; dilatation of pupils; skin cool; no unnatural action about the carotids; spasms of the limbs increased, and extending to the muscles of the spine, producing occasionally a state of opisthotonos. The chloroform was again administered, and he remained very quiet during the day, sleeping at intervals. The chloroform was used again in the evening. The emaciation was very marked, and to a greater extent than we had ever seen it in any other disease of the same duration. $\mathrm{He}$ was ordered wine and brandy, with arrowroot and beef-tea.

22nd.-This morning we found him worse again; total deprivation of all his mental faculties. Ordered, an ointment of tartar-emetic and croton oil, to be rubbed over the whole extent of the spine. Ice to be applied to the head, and to have the chloroform. In the evening, symptoms somewhat better; chloroform repeated. 
23rd.-Has passed a more comfortable night: the conjunctivæ less suffused; countenance more intelligent; tongue becoming moist and less red; pulse ninety-four; bowels constipated. Ordered, one drop of croton oil, every four hours; chloroform repeated.-Evening: appears better in every respect; the bowels have acted. Ordered, muriate of morphia, one grain, to be taken immediately; and chloroform.

24th.-Had several hours sleep, and is more sensible; complains of his hands and feet feeling cold. The ice to be discontinued, and to have hot water to the feet. Ordered, chloric ether, half an ounce, carbonate of ammonia half a drachm, camphor mixture seven ounces and a half. Mix. An ounce to be taken every three hours.-Evening: better in every respect, except that the pulse has got up to 120 ; this might be attributed to his having had too many of his friends seeing him. Gave the chloroform, and in fifteen minutes we found the pulse had come down to eighty-eight. Repeat the morphia and mixture.

25th.- Has had an excellent night; returning intelligence; pulse ninety-four; skin warm; still passes his urine and stools under him; expression of countenance improving. From this time the improvement was so rapid and continuous that $I$ shall not consider it necessary to describe the symptoms daily. The chloroform was administered occasionally, with tonics and stimulants; and in about a fortnight he went into the country, quite well both in mind and body.

Liverpool, 1848.

\section{ON A CASE OF}

ABSCESS OF THE THORACIC WALLS, SIMULATING PLEURITIS AND EMPYEMA.

BY HENRY CRISP, M.B. Lond.

The following case occurred in the practice of my friend Mr. Martin, of Haverhill, Suffolk, who kindly gave me an opportunity of watching the patient throughout. It is interesting, from its similitude to an attack of pleuritis, under which disease, indeed, the patient was at first supposed to be labouring. It has also some points of analogy with the case reported in the number of The LANCET for July 1st, p. 16, by Dr. Macdonnell, of Montreal.

On the first appearance of the swelling it might have been supposed that there was a collection of pus in the pleura, which was making its way externally; but there were no stethoscopic signs which would indicate the presence of empyema.

J.S-, twenty-two years of age, cabinet-maker, of rather intemperate habits, was attacked, in February, 1848, with pain of a sharp, stabbing character in the right side; he was of unhealthy appearance, and one or two members of his family had died of phthisis. The pain was aggravated by making pressure over and between the ribs, by taking a full inspiration, by coughing, and by any motion of the affected side. There was no audible "rubbing sound," nor dulness on percussion. Large crepitation could be heard on both sides of the chest, and the respiratory murmur was present in all parts of the lungs, though very feeble. He had a slight cough, and expectorated a moderate quantity of transparent, viscid mucus; respiration was slightly quickened, and the intercostal muscles of the affected side did not act so freely as those of the other side. These symptoms had been preceded by slight shivering; pulse-about 80 , small and weak; tongue furred; bowels confined; and he had slight thirst. He was ordered aperient medicines, with small doses of tartar-emetic every five hours, and a mild mercurial at night. This treatment was continued for some time, the patient occasionally feeling better, but never entirely losing the pain. The cough still continued, but he was not confined to his bed; his tongue was always much furred, and great difficulty was experienced in getting his bowels to act properly. His pulse was, for the most part, quicker than natural; his appetite was variable, but generally good.

About three weeks from the appearance of these symptoms, he first noticed a swelling over the site of the pain, just below the right mamma; this was boggy and diffusednot very painful on pressure. At first there was little redness, but after a short time the integuments became of a pinkish hue. 'There was no dulness of the affected side; the respiratory murmur, though very faint on both sides, was audible all over the chest; pulse about 90 , weak; bowels constipatedmotions very dark-coloured; his cough still troubles him, and much increases the pain in the side.

Abont a week after this he had rigors; the swelling became softer, and matter was detected; though this was at first deep- eated, pressure did not empty the sac. Leeches and hot fomentations were employed when the swelling first made its ppearance, and appropriate medicines given internally. $\mathbf{H e}$ became very low; the pulse was quick, weak, and irritable; his tongue was covered with a thick dark fur, and he lost his appetite; the pain was so severe as to prevent his sleeping. Poultices were applied for a few days, and then the abscess was opened. About a teacupful of white, inodorous pus scaped.

Poultices were continued; ammonia and wine, and afterards quinine, were given internally.

He was very much relieved by the evacuation of the abscess: he slept better, his appetite returned, and he lost his cough entirely. In two or three days, the wound, which had discharged a little, entirely closed, and he gradually but perfectly recovered his former health.

London, July, 1848.

\section{ON PYROGEN-ONLY ONE ELECT'RIC FLUID- MAGNETISM A PROPERTY OF PYROGEN.}

\section{BY JOHN J. LAKE, Esq., Portsmouth.}

IN my last communication on this subject, (THE LANCET, April 22nd, p. 447,) it is stated that potassium was first obtained by the withdrawal of pyrogen from moistened hydrate of potash. This is assuming that there is only one kind of fluid, which I have designated pyrogen, and not two, according to the now commonly adopted hypothesis.

In advocating the old but neglected theory of Watson, Franklin, and other fathers of this branch of science, it will be necessary to answer some objections that have been advanced with effect against it; and this will lead to the consideration of some difficulties in the way of adopting the opposite theory of two fluids. For instance, it is received that two pith balls, suspended by silk threads, when in a negative state, mutually " repel each other;" and it has been deemed impossible to account for the absence of fluid producing such an effect. This, the usual manner of describing the visible appearances, is greatly calculated to conceal the real cause. Two balls, thus suspended, and in a negative state, do not repel each other. They diverge from a common point, but exert upon each other no particular pyrogenic influence. This point is the centre of a pyrogenic vacuum, (not a vacuum of all matter, but a deficiency of pyrogen, ) of greater or less extent, created in the atmosphere, as well as on the balls, owing to the latter attracting the portion of pyrogen in their immediate neighbourhood. The fluid without this vacuum necessarily endeavours to fill it up, and in seeking to do so, draws the pith halls towards it, as a ready medium of transport, the lightness of the pith enabling it to do so. In like manner, when they are charged to excess with pyrogen, the fluid, seeking to diffuse itself, and restore the equilibrium, carries them outwards along with it, and for the same reason.

Again, when a card, or pack of cards, or folds of paper, are pierced by a discharge of pyrogen, there is a mark observed by the side of the hole, indicating a current in the opposite direction to that discharged, but parallel with it. This is usually viewed as proving the existence of a current of negative fluid. It is not, however, by any means a sure sign of the motion of two fluids, because, first, supposing two fluids, they should move with equal force, and each make a complete perforation; secondly, on the same supposition, they ought not to move parallel at all, but take the shortest path to meet and unite with each other, and so restore their equilibrium; for on this hypothesis " the particles of each fluid are conceived to exert upon each other a strong repulsive force; while particles of the unlike fluids mutually attract each other." And it is difficult to imagine how it can be supposed, that on completing the circuit of a battery the positive and negative fluids are compelled, by acting against each other, to move spirally about the wire, since the mutual attraction they are assumed to have for each other should effect a combination, and thus stay their progress.*

* On the theory of two fluids, it would be impossible to construct a galvanic battery of more than one pair of plates. Beyond this, each plate would neutralize the effect produced by the one in the adjoining division of the trough to which it is united; for, supposing each to produce an equal quantity of its particular fluid, the one would be absorbed by the other as fast as generated. This, however, is contrary to experience, for the quantity of fluid generated in a battery is in proporition to the number and size of the plates. Then, on completing the circuit, the attraction supposed to exist between the two fluids should stop their progress, and they should combine with each other, and not make a continual circuit in opposite directions, opposing each other so strongly as to cause each to deviate from with the hypothesis of one fluid. 